\title{
Optimal Lot Size, Price and Backorder Level for A Production Inventory Model With Partial Backlogging
}

\author{
Subhankar Adhikari \\ Department Of Mathematics, Chandernagore College, Chandernagore-712136 \\ Email: subhankar_adhikari@yahoo.com
}

\begin{abstract}
A single stage production inventory model incorporating shortage was developed. Shortage was partially backlogged at a constant rate. Here the demand is taken to be monotonic decreasing function of selling price. Linear price dependent demand pattern is taken into consideration. Profit maximization problem is formulated. Decision variables are lot size, price and backorder level. A numerical example is given in support of the model. Sensitivity analysis of key parameters has been performed to test feasibility of the model.
\end{abstract}

Keywords-Inventory; Production; Pricing; Partial Backlogging

\section{INTRODUCTION}

Many inventory models have been framed by taking demand constant. But in real life it is a very rare situation. There are many aspects which can influence demand. Price is one of them. Generally there is an inverse relation between price and demand. As price increases demand decreases. Very often price has to forecast before the starting of the inventory cycle. In many shops, malls price has been displayed on the board for a commodity. Also we have seen shop of fixed price. Two common questions are very familiar with a production inventory model. How much quantity manufacturer has to produce and what will be the price of the quantity?

Shortage is a common thing in inventory. Producer cannot produce more and more. As holding cost play an important role in determining cost function. Simply if one produces much with respect to demand then he has to hold more quantity. Also if an item deteriorates with time then producer has to be careful about the amount of holding of quantity. When shortage occurs two situations may appear. One is complete backlogging while other is partially backlogging. Partial backlogging is more natural incident during shortage. During stock out period customer becomes impatient. A fraction of demand is lost. Considering all these situations a production inventory model has been formulated with partial backlogging of shortages under price dependent demand.

\section{LITERATURE SURVEY}

Abad in his work [1] introduced the concept of pricing in inventory model. Two types of different customer functions were introduced. San Jose et.al [2] showed exponential partial backlogging. A price sensitive deteriorating inventory model with quantity discount was developed by Wee [3]. An EPQ model where the backorders were planned was developed by Cardenas Barron [4]. Sana [5] studied a price sensitive inventory model for perishable goods. A production inventory model with probabilistic deterioration was formulated by Sarkar[6]. Taleizadeh et.al [7] studied an economic order quantity model with discount policy in backlogging situation. Works of Pal et.al [8] and
Taleizadeh et.al [9] on pricing strategy in multistage model are noteworthy.

\section{ASSUMPTIONS}

- A single stage inventory model is considered

- Production rate is constant

- Demand rate is a monotonic decreasing linear function of selling price.

- Production rate is greater than demand rate.

- Inventory cycle starts with shortage.

- Time horizon is taken to be infinite

- Backlogging rate is constant

- Cost of lost sale is taken into account

- Terminal inventory is zero.

\section{NOTATIONS}

\begin{tabular}{|c|l|}
\hline Symbol & Meaning \\
\hline$p$ & Production rate \\
\hline$s$ & Selling price \\
\hline$d(s)$ & Demand rate \\
\hline$Q$ & Lot size \\
\hline$w$ & Back order level \\
\hline$I(t)$ & Inventory level at time t \\
\hline$c_{b}$ & Back order cost of an unit \\
\hline$c_{l}$ & Lost sale cost of an unit \\
\hline$c_{h}$ & Holding cost of an unit \\
\hline$c_{p}$ & Production cost of an unit \\
\hline$k$ & Set up cost \\
\hline$A T P$ & Average total profit \\
\hline$\beta$ & Backlogging rate \\
\hline
\end{tabular}

\section{MODEL FORMULATION}

Here a single stage production inventory model with partial backlogging of shortages on infinite time horizon is formulated. Inventory cycle starts with shortage. Stock out period is $\left[0, t_{1}\right]$. Production starts at the time $t=t_{1}$. The amount which is produced during the period $\left[t_{1}, t_{2}\right]$ is required to meet backorder. Production for the period $\left[t_{2}, t_{3}\right]$ is used to build inventory at the rate $P-d(s)$.Production stops at the time $t=t_{3}$. Production period is given by $\left[t_{1}, t_{3}\right]$. Inventory exhausts at a rate $-d(s)$ for the time interval 


\section{International Journal of Research in Advent Technology, Vol.7, No.5, May 2019 \\ E-ISSN: 2321-9637}

\section{Available online at www.ijrat.org}

$\left[t_{3}, t_{4}\right]$. Inventory cycle completes at time $t=t_{4}$. In this model profit maximization problem is developed. Decision variables are lot size, selling price and back order level.

\section{EQUATIONS}

Differential equation governing inventory level for the time interval $\left[0, t_{1}\right]$ is given by

$\frac{d I}{d t}=-d(s) \beta$ Subject to boundary conditions $I(0)=$ 0 and $I\left(t_{1}\right)=-w$

The solution of the differential equation using initial condition $I(0)=0$

$I(t)=-d(s) \beta t$

Now using the relation $I\left(t_{1}\right)=-w$ we get $t_{1}=\frac{w}{d(s) \beta}$

Back order cost for the period $\left[0, t_{1}\right]$ is given by $c_{b} \int_{0}^{t_{1}}(-I(t) d t)$

$=\frac{c_{b}}{2} \frac{w^{2}}{d(s) \beta}$

For the above mentioned time interval unsatisfied demand is $d(s)(1-\beta)$. So the cost of lost sale for this period is given by $c_{l} \int_{0}^{t_{1}} d(s)(1-\beta) d t$

$=\frac{c_{l}(1-\beta)}{\beta} w$

Differential equation governing the inventory level for the time period $\left[t_{1}, t_{2}\right]$ is given by

$\frac{d I}{d t}=p-d(s)$

subject to the conditions $I\left(t_{1}\right)=-w, I\left(t_{2}\right)=0$

The solution of the differential equation using terminal condition $I\left(t_{2}\right)=0$

$I(t)=\{p-d(s)\}\left(t-t_{2}\right)$

Using the condition $I\left(t_{1}\right)=-w$ in the above equality we get

$t_{2}=t_{1}+\frac{w}{p-d(s)}$

Back order cost for the period $\left[t_{1}, t_{2}\right]$ is given by $c_{b} \int_{t_{1}}^{t_{2}}(-I(t) d t)$

$=c_{b} \frac{w^{2}}{2\{p-d(s)\}}$

Differential equation governing the inventory level for the time period $\left[t_{2}, t_{3}\right]$ is given by

$\frac{d I}{d t}=p-d(s) \quad$ subject to the conditions, $I\left(t_{2}\right)=0$

Here the inventory level is same as given in the relation (5)

Holding cost for the time period $\left[t_{2}, t_{3}\right]$ is given by $c_{h} \int_{t_{2}}^{t_{3}} I(t) d t$

$=c_{h} \frac{\{p(-Q+w)+d(s) Q\}^{2}}{2\{p-d(s)\} p^{2}}$

It should be noted that here we use the relation

Production time $=\frac{Q}{p}=t_{3}-t_{1}$

Differential equation governing the inventory level for the time period $\left[t_{3}, t_{4}\right]$ is given by

$\frac{d I}{d t}=-d(s) \quad$ subject to the conditions, $I\left(t_{4}\right)=0$

The solution of the differential equation is given by

$I(t)=d(s)\left(t_{4}-t\right)$
Holding cost for the time period $\left[t_{3}, t_{4}\right]$ is given by $c_{h} \int_{t_{3}}^{t_{4}} I(t) d t$

$=c_{h} \frac{\{d(s) Q \beta+p(w-Q \beta)\}^{2}}{2 d(s) p^{2} \beta^{2}}$

Total cost is formed by purchase cost, set up cost, back order cost, lost sale cost, holding cost.

Total revenue is given by

$=s Q$

Average total profit $=($ total revenue- total cost $) /$ cycle length. Cycle length is the ratio of amount consumed and demand rate. So cycle length is given by

$=\frac{Q}{d(s)}$

After some algebraic simplification average total profit (ATP) is given by

$\mathrm{ATP}=a_{1} Q \Psi(s)+d(s)\left(s-c_{p}\right)+a_{2} w-$ $a_{3} w d(s)+\frac{1}{2 Q}\left[\left\{a_{4}-a_{5} w+\frac{a_{6} w^{2}}{\Psi(s)}\right\} d(s)+a_{7} w^{2}\right]$

Where

$$
\begin{aligned}
& a_{1}=\frac{c_{h}}{2 p} \\
& a_{2}=\frac{c_{h}}{\beta} \\
& a_{3}=\left(\frac{1-\beta}{\beta}\right) \frac{c_{h}}{p} \\
& a_{4}=-2 k \\
& a_{5}=\frac{2 c_{l}(1-\beta)}{\beta} \\
& a_{6}=c_{b}+c_{h} \\
& a_{7}=-\left(\frac{c_{h}+c_{b} \beta}{\beta^{2}}\right) \\
& d(s)=a-b s \\
& \Psi(s)=a-b s-p
\end{aligned}
$$

\section{SOLUTION PROCEDURE}

Necessary condition for maximization is $\frac{\partial}{\partial Q}(A T P)=0, \frac{\partial}{\partial s}(A T P)=0$ and $\frac{\partial}{\partial w}(A T P)=0$

From these equations we can obtain optimal values of lot size, price and back order level as $Q^{*}, s^{*}$ and $w^{*}$ Sufficient condition for optimality

The Hessian matrix given below

$$
\left(\begin{array}{ccc}
\frac{\partial^{2}}{\partial Q^{2}}(A T P) & \frac{\partial^{2}}{\partial Q \partial s}(A T P) & \frac{\partial^{2}}{\partial Q \partial w}(A T P) \\
\frac{\partial^{2}}{\partial Q \partial s}(A T P) & \frac{\partial^{2}}{\partial s^{2}}(A T P) & \frac{\partial^{2}}{\partial s \partial w}(A T P) \\
\frac{\partial^{2}}{\partial Q \partial w}(A T P) & \frac{\partial^{2}}{\partial s \partial w}(A T P) & \frac{\partial^{2}}{\partial s^{2}}(A T P)
\end{array}\right)
$$

is negative definite at $Q=Q^{*}, s=s^{*}, w=w^{*}$

We solve this problem numerically with the help of MATHEMATICA SOFTWARE (version 10.4)

\section{NUMERICAL EXAMPLE}

The following data is used

Back order cost per unit item $c_{b}=\$ 2$, Lost sale cost per unit item $c_{l}=\$ 2.5$, Holding cost per unit item per unit time $c_{h}=\$ 1$, Production cost per unit item $c_{p}=\$ 3$, Set up cost $k=\$ 500$, Production rate $p=1000$, Parameter associated with demand rate $a=300, b=$ $0.7, \beta=0.8$ 


\section{International Journal of Research in Advent Technology, Vol.7, No.5, May 2019 \\ E-ISSN: 2321-9637 \\ Available online at www.ijrat.org}

We obtain optimal values of lot size, price and back order level $Q^{*}=417.81$ unit, $s^{*}=\$ 144.97$ and $w^{*}=$ 102.59 unit .

Optimal average total profit $=\$ 13736.10$. These solutions are optimal since eigen values of the hessian matrix stated above are $-1.40006,-0.00114305,-0.00122761$. So the hessian matrix is negative definite.

\section{SENSITIVITY ANALYSIS}

\begin{tabular}{|c|c|c|c|c|c|}
\hline Parameter & $\begin{array}{l}\text { Percentage } \\
\text { change in } \\
\text { parameter }\end{array}$ & $\begin{array}{l}\text { Percentage } \\
\text { change in ATP }\end{array}$ & $\begin{array}{l}\text { Percentage } \\
\text { change in } Q\end{array}$ & $\begin{array}{l}\text { Percentage } \\
\text { change in } w\end{array}$ & $\begin{array}{l}\text { Percentage } \\
\text { change in } s\end{array}$ \\
\hline \multirow[t]{4}{*}{$c_{h}$} & -20 & .14 & 7.47 & -9.03 & -0.03 \\
\hline & -10 & .06 & 3.38 & \begin{tabular}{|l|} 
\\
\end{tabular} & -0.01 \\
\hline & 10 & -0.06 & -2.86 & 3.84 & 0.01 \\
\hline & 20 & $\begin{array}{l}-0.11 \\
\end{array}$ & \begin{tabular}{|l|} 
\\
\end{tabular} & 7.32 & 0.03 \\
\hline \multirow[t]{4}{*}{$k$} & -20 & 0.18 & \begin{tabular}{|l|}
-10.64 \\
\end{tabular} & -12.11 & \begin{tabular}{|l|}
-0.03 \\
\end{tabular} \\
\hline & -10 & 0.09 & \begin{tabular}{|l|}
-5.17 \\
\end{tabular} & -5.89 & -0.01 \\
\hline & 10 & -0.08 & 4.91 & 5.59 & 0.02 \\
\hline & 20 & -0.16 & 9.60 & 10.93 & 0.04 \\
\hline \multirow[t]{4}{*}{$P$} & -20 & 0.02 & 1.31 & -1.21 & -0.01 \\
\hline & -10 & 0.01 & 0.57 & -0.54 & -0.01 \\
\hline & 10 & -0.01 & -0.46 & 0.43 & 0.01 \\
\hline & 20 & -0.02 & \begin{tabular}{|l|}
-0.86 \\
\end{tabular} & 0.79 & 0.02 \\
\hline \multirow[t]{4}{*}{$a$} & -20 & -36.81 & -11.59 & -8.47 & -19.65 \\
\hline & -10 & \begin{tabular}{|l|}
-19.45 \\
\end{tabular} & \begin{tabular}{|l|}
-5.67 \\
\end{tabular} & -4.04 & -9.82 \\
\hline & 10 & 21.54 & 5.46 & 3.68 & 9.83 \\
\hline & 20 & 45.16 & 10.76 & 7.08 & 19.67 \\
\hline \multirow[t]{4}{*}{$b$} & -20 & 26.00 & 0.16 & 0.12 & 24.64 \\
\hline & -10 & 11.55 & 0.08 & 0.05 & 10.95 \\
\hline & 10 & -9.45 & -0.08 & -0.06 & -8.95 \\
\hline & 20 & -17.33 & \begin{tabular}{|l|}
-0.17 \\
\end{tabular} & -0.12 & -16.43 \\
\hline \multirow[t]{4}{*}{$\beta$} & -20 & -0.05 & 2.81 & -15.85 & 0.03 \\
\hline & \begin{tabular}{|l|}
-10 \\
\end{tabular} & -0.02 & 1.35 & -7.82 & 0.02 \\
\hline & 10 & 0.02 & -1.28 & 7.58 & -0.01 \\
\hline & 20 & 0.04 & -2.48 & 8.17 & -0.03 \\
\hline
\end{tabular}

- As holding cost increases average profit and lot size decreases while back order level increases. So it can be stated that higher holding cost indicates smaller lot size. More shortage can be allowed in this situation

- With the increase of set up cost lot size, back order level increases and average profit decreases. Large set up cost indicates that the number of set up should be small in number. So large lot is preferable in this situation.
- When production rate increases the changes in quantities are small. Average profit and lot size decreases while price increases.

- With the increase of $a$ average profit increases largely. Selling price, lot size and back order level increases for large value of $a$. This is for the fact that demand rate varying positively with the value of $a$.

- When $b$ increases average profit and selling price decreases largely. Lot size and back order level also decreases slightly

- As $\beta$ increases back order level increases much. Amount of back order should be large in this situation. Lot size decreases with the higher value of $\beta$.

\section{CONCLUSIONS AND FUTURE DIRECTIONS OF RESEARCH}

A single stage production inventory model with price sensitive demand is studied in this paper. Shortage is allowed and partially backlogged at a constant rate. From numerical study it seems to be a profitable one. Average profit decreases when different cost components increases. Average profit increases when demand rate increases. Demand rate is positively influenced by value of the parameter $a$. When $a$ increases $20 \%$ average profit increases $45 \%$.. Demand rate is negatively influenced by value of the parameter $b$. . When the value of $b 20 \%$ decreases average profit increases $25 \%$. Back order level increases when holding cost, set up cost and backlogging rate increases. Significantly it increases highest $11 \%$ when set up cost increases $20 \%$. Back order level decreases almost $16 \%$ when backlogging rate $\beta$ decreases $20 \%$. It can be stated that back order quantity increases mostly with higher set up cost and decreases mostly with decreasing backlogging rate. From the study of table of sensitivity analysis it can be stated that this model is stable as there is no huge change in quantities as different parameter changes. This model can be extended by incorporating the effect of deterioration. Also multi stage model can be formed by extending this model. 


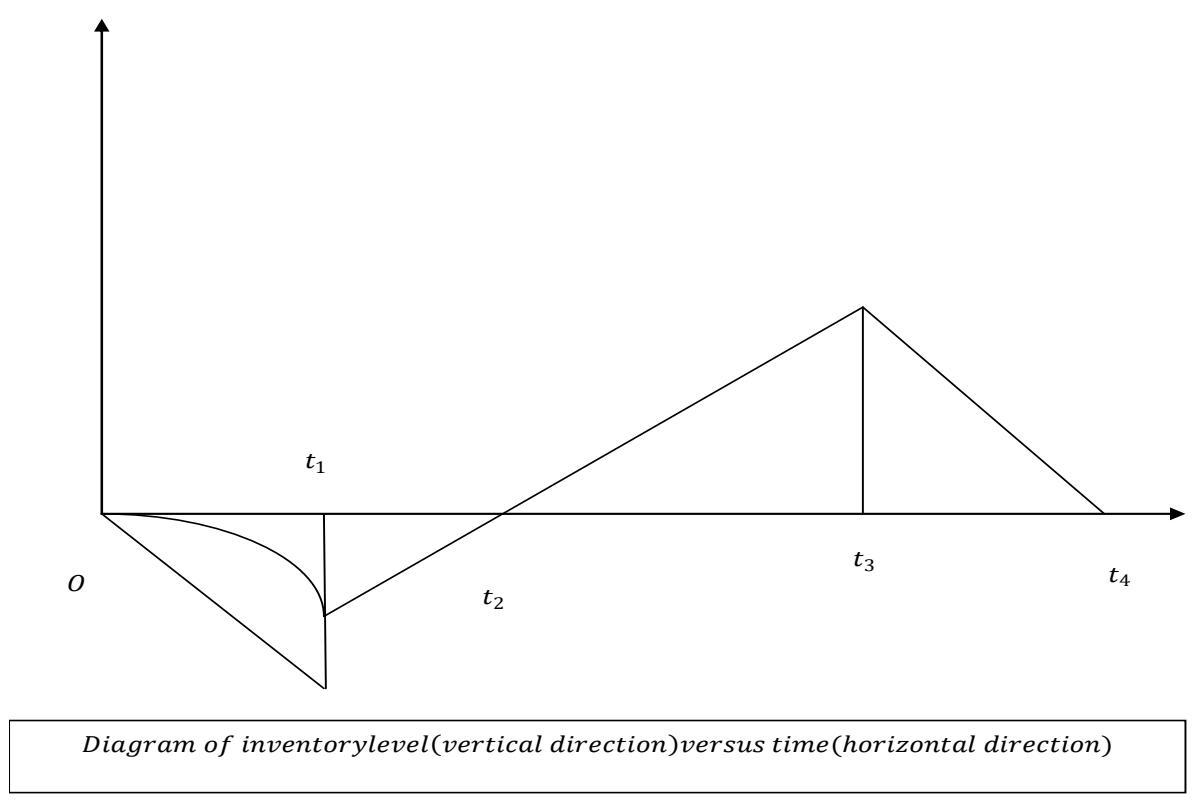

Fig. 1.

\section{REFERENCES}

[1] P.L .Abad. "Optimal pricing and lot size under condition of perishbility and parial backordeing". Management Science, pages 1093-1104, 42(8), 1996.

[2] L.A. San Jose, J.Sicilia and J. Garcia-Laguna. "Analysis of inventory system with exponential partial backordering", International Journal of Production Economics, pages 76-86,100(1),2006.

[3] H.M.Wee. “ Deteriorating inventory model with quality discount, pricing and partial backordering", International Journal of Production Economics, pages 511-518,59,1999

[4] L.E. Cardenas Barron, "Economic production quantity with rework process at a single stage manufacturing system with planned backorders", Computers and Industrial Engineering, pages 11051113,57(3),2009

[5] S.S. Sana. "Price-sensitive demand for perishable items- an EOQ model", Applied Mathematics and Computation, pages 6248-6259,217,2011

[6] B.Sarkar. " A production-inventory model with probabilistic demand in two-echelon supply chain management", Applied Mathematical Modelling, pages $3138-3151,37,2013$

[7] A.A. Taleizadeh , D.W. Pentico. " An economic order quantity model with partial backordering and all-units discount", International Journal of Production Economics, pages 172-184,155,2014

[8] B. Pal, S.S. Sana, K.S. Chaudhury. “ Joint pricing and ordering policy for two echelon imperfect production inventory model with two cycles", International Journal of Production Economics, pages229-238,155,2014

[9] A.A. Taleizadeh, M. Noori-daryan. "Pricing, manufacturing and inventory policies for raw materials in athree-level supply chain", International Journal Of System Science, pages 919-931, 47(4), 2016. 